Article

\title{
Plasma Surface Functionalization of Carbon Nanofibres with Silver, Palladium and Platinum Nanoparticles for Cost-Effective and High-Performance Supercapacitors
}

\author{
Zelun Li, Shaojun Qi, Yana Liang, Zhenxue Zhang, Xiaoying Li@ and Hanshan Dong * \\ School of Metallurgy and Materials, University of Birmingham, Birmingham B15 2TT, UK; \\ zl381@cam.ac.uk (Z.L.); S.Qi@bham.ac.uk (S.Q.); YXL452@student.bham.ac.uk (Y.L.); \\ z.zhang.1@bham.ac.uk (Z.Z.); X.li.1@bham.ac.uk (X.L.) \\ * Correspondence: h.dong.20@bham.ac.uk; Tel.: +44-121-414-7105
}

Received: 5 October 2018; Accepted: 19 December 2018; Published: 21 December 2018

check for updates

\begin{abstract}
Due to their relatively low cost, large surface area and good chemical and physical properties, carbon nanofibers (CNFs) are attractive for the fabrication of electrodes for supercapacitors (SCs). However, their relatively low electrical conductivity has impeded their practical application. To this end, a novel active-screen plasma activation and deposition technology has been developed to deposit silver, platinum and palladium nanoparticles on activated CNFs surfaces to increase their specific surface area and electrical conductivity, thus improving the specific capacitance. The functionalised CNFs were fully characterised using scanning electron microscope (SEM), energy dispersive X-ray analysis (EDX) and X-ray diffraction (XRD) and their electrochemical properties were evaluated using cyclic voltammetry and electrochemical impedance spectroscopy. The results showed a significant improvement in specific capacitance, as well as electrochemical impedance over the untreated CNFs. The functionalisation of CNFs via environmental-friendly active-screen plasma technology provides a promising future for cost-effective supercapacitors with high power and energy density.
\end{abstract}

Keywords: carbon nanofibres (CNFs); active-screen plasma sputtering (ASPS) technology; supercapacitors (SCs); silver (Ag); platinum $(\mathrm{Pt})$ and palladium $(\mathrm{Pd})$ nanoparticles

\section{Introduction}

The enormous growth of electric vehicles and portable electronic devices has boosted the needs for energy storage devices simultaneously with high power and energy density. The most common energy storage devices are batteries, fuel cells and supercapacitors (SCs). The latter have attracted significant attention and research progress due to their advantageous properties over the formers. SCs exhibit greater power density satisfying the increasing demand for high power electrical appliances and fast charging, and they can withstand larger numbers of charge-discharge cycles [1,2]. However, SCs suffer from lower energy densities, high costs of raw materials and manufacturing which limit their widespread use and commercialisation [3-11]. One of the most crucial and greatest challenges to achieve these targets is indeed control of nanoscale materials and structures used for the SCs [12-14]. A large quantity of processing methods have been presented to fabricate SC electrodes based on carbon materials [15], especially carbon nanoparticles, graphene and carbon nanotubes (CNTs) $[16,17]$. In the past few years, two-dimensional (2D) nanomaterials including graphene, graphene-like materials, such as MXenes and transition-metal dichalcogenide (TMDs) have been explored to develop supercapacitors with enhanced electrochemical performance [18-25]. 
The energy storage in SCs is based on the electrostatic forces in the formation of an electrochemical double layer (EDL) between electrons and ions as well as fast redox reaction. Theoretically, the energy density of a supercapacitor is proportional to the specific capacitance and the operating cell voltage, given below $[1,26,27]$

$$
E_{s}=\frac{1}{2} C_{s} \Delta V^{2}
$$

where $E_{s}$ is the energy density, $C_{S}$ is the specific capacitance, and $\Delta V$ is the operating cell voltage. Therefore, improved energy density can be achieved through increasing specific capacitance and extending operating cell voltage. According to Equation (2), specific capacitance of an electrode is dependent of the surface area of the electrode [1], therefore materials with a high surface area are preferable for electrode fabrication.

$$
C_{s}=\frac{\varepsilon A}{m d}
$$

where $\varepsilon$ is the electrolyte dielectric constant, $A$ is the surface area of the electrode material, $d$ is the effective thickness of the EDL, and $m$ is the mass of the electrode material. Also, it is crucial to retain high power density when improving energy density. Power density of supercapacitors is associated with the rate capability of electrodes which reflects how fast charge/discharge cycling can be when good capacitive behaviour is maintained. Rate capability of electrode materials is related with their electrochemical impedance, and hence low electrochemical impedance is also demanded for electrode materials [28].

Carbon materials such as carbon nanotubes (CNTs) and carbon nanofibres (CNFs) are considered as good anode materials for SCs due to their accessibility, chemical inertness in different solutions, easy processability and good temperature tolerance [29-32]. Also, many physical and chemical active methods allow for production of the material with an improved surface area and a controllable pore structure $[29,32,33]$. Although CNTs show unique tubular porous structures and prominent electrical properties [15], their applications are limited by the production costs [32]. Instead, inexpensive CNFs can be easily manufactured using different methods such as electrospinning [34-36] or vapor growth $[37,38]$. Also, CNFs are easy to disperse, process and functionalise achieving high conductivity and improved surface area. Therefore, CNFs have attracted great interest for making cost-effective supercapacitor electrodes. It was found that electrical conductivity of CNT films could be increased following the deposition of metallic nanoparticles such as gold, silver, platinum and palladium on CNTs by plasma sputtering [18]. Active-screen plasma sputtering technology offers a green and easy route to achieve the deposition of metallic nanoparticles [39-42], compared to electrochemical [43,44] and electroless deposition $[45,46]$ because the former is a physical deposition method which does not involve disposal of polluting wastes or chemicals.

This work aimed at functionalising the inexpensive CNFs by coating with $\mathrm{Ag}, \mathrm{Pt}$ and $\mathrm{Pd}$ nanoparticles via the environmentally-friendly active-screen plasma sputtering and hence improving their electrochemical properties. The results showed that the specific capacitance and electrochemical impedance of CNFs were improved significantly and good cyclability was achieved.

\section{Materials and Methods}

\subsection{Sample Preparation}

CNFs were supplied by Sigma-Aldrich Company Ltd. (Dorset, UK) and they were pyrolytically stripped. The carbon content is more than $98 \%$ with trace amounts of sulphur, calcium, silicon, nickel, chromium, sodium, magnesium and iron. Commercial CNF powders (Sigma-Aldrich) (5 g) were dispersed in isopropanol $(20 \mathrm{~mL})$, provided by Struers (Catcliffe, UK), to form a suspension which was then sonicated at a power of $200 \mathrm{~W}$ for $1 \mathrm{~h}$ to disperse the CNFs. The suspension was distributed into glass Petri dishes (54 mm dimeter) and left to dry overnight, allowing the CNFs attaching to the Petri dishes. 


\subsection{Active-Screen Plasma Sputtering (ASPS)}

The setup of active-screen plasma sputtering (ASPS) is demonstrated in Figure 1. The Petri dishes including CNFs were introduced in the vacuum chamber of a laboratory scale modified DC furnace (Klöckner Ionon GMBH, Bergisch Gladbach, Germany) with different targets of silver, palladium and platinum (specification: $80 \mathrm{~mm} \times 80 \mathrm{~mm} \times 0.2 \mathrm{~mm}$; purity: $99.99 \%$; Birmingham Metal Co. Ltd., Birmingham, UK), respectively. The distance between target plates and Petri dishes was $33 \mathrm{~mm}$. ASPS was carried out at $320^{\circ} \mathrm{C}$ at a heating rate of $500^{\circ} / \mathrm{h}$ in an atmosphere containing $75 \%$ hydrogen and $25 \%$ argon at a pressure of 0.75 mbar. The treatment time ranged from 0.1 to $1.0 \mathrm{~h}$. The sample codes and treatment details are listed in Table 1.

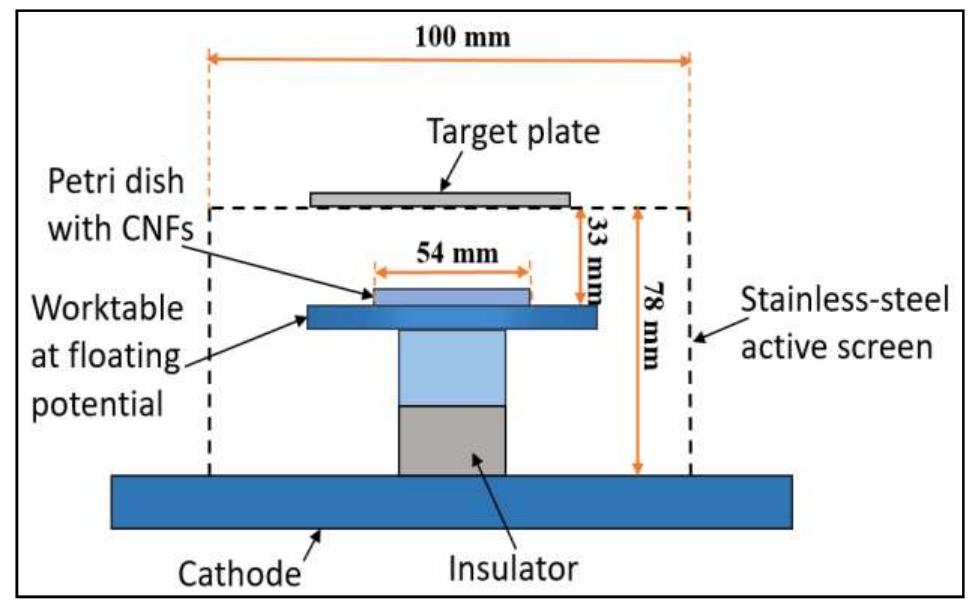

Figure 1. Schematic diagram of the active-screen plasma sputtering (ASPS) setup inside the plasma furnace.

Table 1. Experimental conditions of active-screen plasma sputtering (ASPS).

\begin{tabular}{|c|c|c|c|c|c|}
\hline Sample Code & Target Material & Gas & Pressure (mbar) & Temperature ${ }^{\circ} \mathrm{C}$ ) & Time (h) \\
\hline CNFs/Ag- $0.1 \mathrm{~h}$ & Silver & & & & 0.1 \\
\hline CNFs/Ag- $0.5 \mathrm{~h}$ & Silver & & & & 0.5 \\
\hline CNFs/Ag-1.0h & Silver & & & & 1.0 \\
\hline CNFs/Pt-0.1h & Platinum & & & & 0.1 \\
\hline $\mathrm{CNFs} / \mathrm{Pt}-0.2 \mathrm{~h}$ & Platinum & $25 \% \mathrm{Ar}+75 \% \mathrm{H}_{2}$ & 0.75 & 320 & 0.2 \\
\hline CNFs/Pt- $0.5 \mathrm{~h}$ & Platinum & & & & 0.5 \\
\hline CNFs/Pd-0.1h & Palladium & & & & 0.1 \\
\hline CNFs/Pd-0.5h & Palladium & & & & 0.5 \\
\hline
\end{tabular}

\subsection{Fabrication of Electrodes}

The structure of the home-made working electrode is shown in Figure 2. A copper wire was cold mounted in a tube using mixture of epoxy resin and epoxy resin hardener. The resin was then ground down until the end of the copper wire was fully exposed. A disc of conductive double-sided copper tape was attached to the end. Before the electrochemical experiment, different CNFs were attached to different conductive tapes, respectively. The weight of the attached CNFs $(m)$ was measured and used to calculate their specific capacitance. 


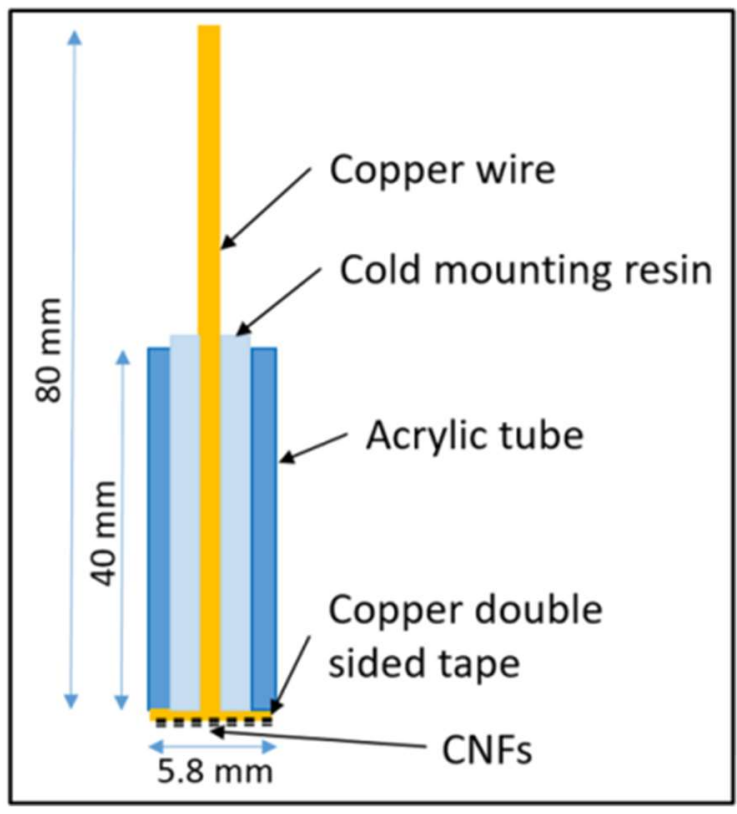

Figure 2. Schematic diagram of the electrodes.

\subsection{Microstructure Characterisation}

Joel 7000 scanning electron microscope (SEM) (Joel, Tokyo, Japan) equipped with an Oxford Inca energy dispersive X-ray spectroscopy (EDX) (Oxford Instruments, Abingdon, UK), was utilised to observe the morphology and collect the elemental information of deposited nanoparticles on CNFs. The phases of nanoparticles were identified using Bruker D8 ADVANCE diffractometer.

\subsection{Electrochemical Test}

Home-made three-electrode cell consisting of a working electrode (CNFs), a saturated calomel electrode (SCE) and a platinum inert counter electrode was designed for half-cell measurement. The solution was $\mathrm{Na}_{2} \mathrm{SO}_{4}$ (anhydrous, $99 \%$ ) in de-ionized water at concentration of $1 \mathrm{M}$. The tests were carried out at room temperature. Cyclic voltammetry (CV) cycled between -0.2 and $-0.7 \mathrm{~V}$ with respect to the SCE at different charge/discharge linear scan rates (i.e. 10, 25, 50, 100 and $200 \mathrm{mV} / \mathrm{s}$ ) unfolded the charging and discharging performance of the working electrode. Cyclic voltammograms were obtained to calculate the specific capacitance of the untreated and functionalised CNFs by Equation (3) [47]. The first few cycles were neglected due to unstable initial conditions caused by electrode activation [48].

$$
C_{s}=\frac{Q}{2 m \Delta V}=\frac{\frac{\int I d V}{v}}{2 m \Delta V}=\frac{\frac{\int \frac{I}{m} d V}{v}}{2 \Delta V}
$$

where $C_{s}$ and $Q$ are the specific capacitance of material and total charge in one cycle under a specific potential scan rate $(v)$, respectively, $I$ is the measured current through the circuit, $V$ is the applied potential (vs. SCE), $\int I d V$ is the integral area of a CV curve integrating the forward and backward scans in the cyclic voltammogram, $\Delta V$ is the operating cell voltage, $J$ is the measured current density.

Electrochemical impedance spectroscopy (Nyquist diagrams) over a frequency range of 0.05 to $100,000 \mathrm{~Hz}$ around the open circuit potential with an alternating current (AC) perturbation of $10 \mathrm{mV}$ revealed the relationship between imaginary and real impedances $\left(Z_{\mid \text {imag } \mid}\right.$ and $\left.Z_{\mid \text {real } \mid}\right)$. CNFs $/ \mathrm{Pd}-0.5 \mathrm{~h}$, $\mathrm{CNFs} / \mathrm{Pt}-0.5 \mathrm{~h}$ and CNFs/Ag-1.0h were then charged and discharged at a constant current density of 2, 0.8 and $0.8 \mathrm{~A} / \mathrm{g}$, respectively, for 2000 cycles to test their cyclability in terms of capacitance retention. 


\section{Results}

\subsection{Microstructure}

Figure 3a-i show the typical morphology of the untreated CNFs and functionalised CNFs. Typical diameters of the CNFs range from 150 to $450 \mathrm{~nm}$. The untreated CNFs have a smooth surface, while the functionalised CNFs have relatively rough surfaces. The EDX results display the chemical composition of the nanoparticles deposited on CNFs. The existence of silver, palladium and platinum elements was detected in functionalised CNFs, respectively. Traces of copper were observed due to the copper tape for SEM sample preparation, and traces of iron and chromium were also identified, which mainly come from the sputtering effect of the active-screen due to plasma bombardment $[40,49]$. Figure $3 \mathrm{~b}-\mathrm{f}$ show that the size of $\mathrm{Ag}$ and $\mathrm{Pd}$ nanoparticles increased with the sputtering time. The size of the $\mathrm{Pd}$ nanoparticles was generally greater than that of $\mathrm{Ag}$ nanoparticles after the same sputtering times $(0.1 \mathrm{~h}$ and $0.5 \mathrm{~h}$, respectively). The particle size of Pd reached up to $250 \mathrm{~nm}$ after sputtering for $0.5 \mathrm{~h}$, while that of $\mathrm{Ag}$ was around $100 \mathrm{~nm}$ after sputtering for $1.0 \mathrm{~h}$. The morphology of the nanoparticles appeared to change from spherical to more nodular with increasing sputtering time. The surface morphology of CNFs/Pd became inhomogeneous after sputtering for $0.5 \mathrm{~h}$, whereas the distribution of the Ag nanoparticles was relatively uniform even after sputtering for $1.0 \mathrm{~h}$. In comparison, the surface morphology of the CNFs $/ \mathrm{Pt}$ was quite different (Figure $3 \mathrm{~g}-\mathrm{i}$ ). The size of the platinum nanoparticles deposited on CNFs was very small and almost remained constant with the sputtering time. The CNFs/Pt achieved a smooth surface finish and a homogeneous as well as fine particle distribution. In addition, there were valleys between the nanoparticles, and the size of these valleys differed with nanoparticle types and sputtering time. For $\mathrm{CNFs} / \mathrm{Ag}$ and $\mathrm{CNFs} / \mathrm{Pd}$, the size of valleys increased with increasing sputtering time, with the valleys becoming large as tens of nanometres after 1.0 and $0.5 \mathrm{~h}$, respectively, whereas the CNFs $/ \mathrm{Pt}-0.5 \mathrm{~h}$ displayed valleys of negligible sizes and remained constant. XRD characterisation revealed equilibrium phase of the deposited element and one of the samples is shown in Figure $3 \mathrm{~m}$. It can be seen that the major peaks of pure silver were identified, indicating the existence of pure silver instead of silver compounds. The peaks of copper were due to the copper tape background. 

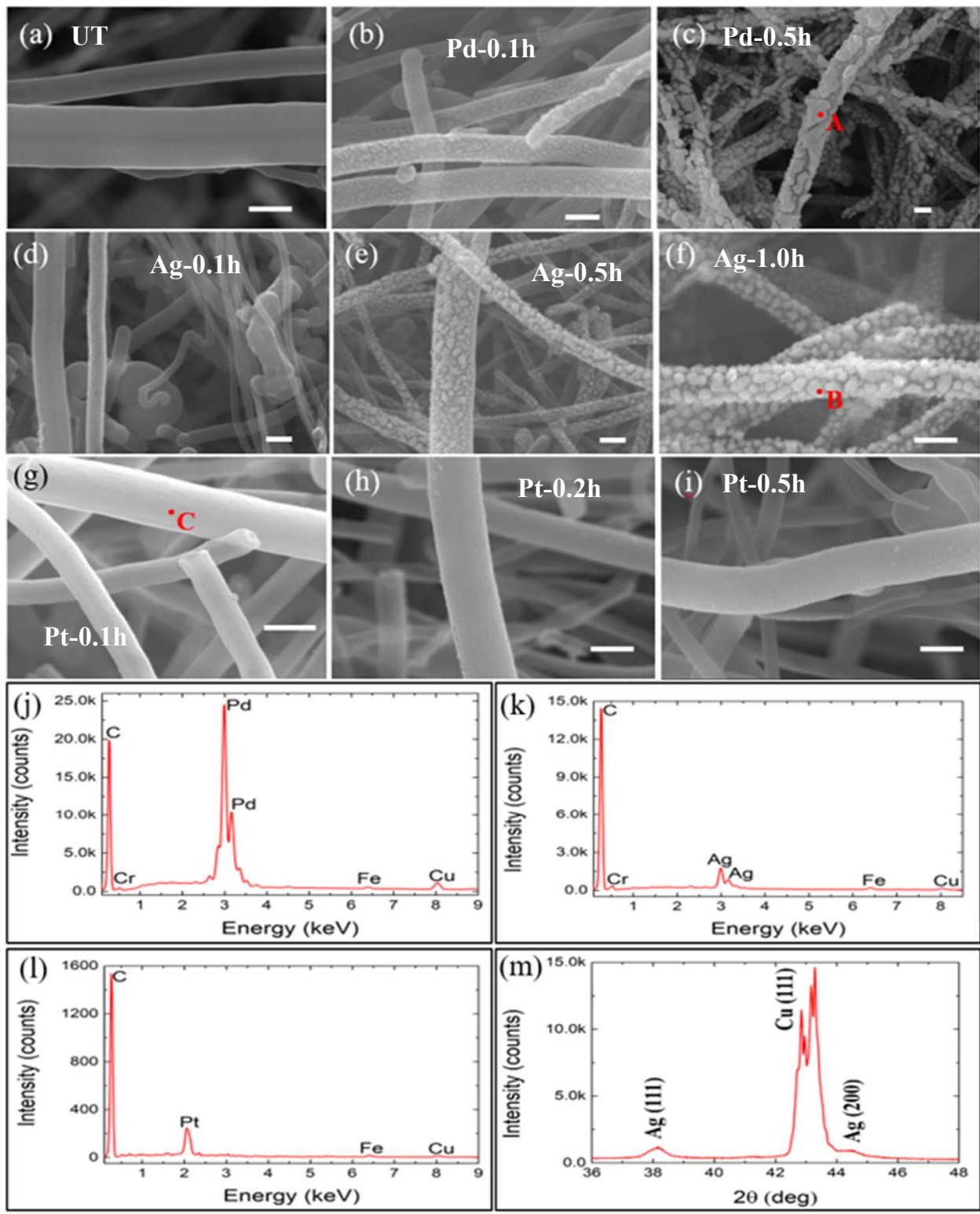

Figure 3. SEM images of: (a) untreated CNFs; (b) CNFs/Pd-0.1h; (c) CNFs/Pd-0.5h; (d) CNFs / Ag-0.1h; (e) CNFs / Ag-0.5h; (f) CNFs / Ag-1.0h; (g) CNFs/Pt-0.1h; (h) CNFs/Pt-0.2h; (i) CNFs /Pt-0.5h. All scale bars are representing $300 \mathrm{~nm}$. EDX spectrum of: (j) CNFs/Pd-0.5h taken from spot 'A', denoted in (c);

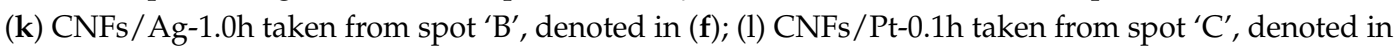
(g). (m) XRD pattern indicating the phase of CNFs/Ag-0.5h.

\subsection{Electrochemical Performance}

Figure $4 a-d$ show typical CV curves of untreated CNFs and functionalized CNFs. The data was taken after 10 cycles. At low scan rates (10 and $25 \mathrm{mV} / \mathrm{s}$ ), all CV curves exhibited quasi-rectangular shapes without obvious redox peaks, demonstrating an appropriate capacitive behavior [50]. However, the distortion from a rectangular shape became more pronounced with increasing scan rates. At high scan rates (100 and $200 \mathrm{mV} / \mathrm{s}$ ), the CV curves of all samples except for CNFs/Ag-1.0h and $\mathrm{CNFs} / \mathrm{Pd}-0.5 \mathrm{~h}$ exhibited considerably huge distortion, indicating poor rate capability of the system [51]. This might attribute to the limited ion-penetration diffusion into the materials, where only the outer surface was in use for charge storage [52]. In comparison, CNFs/Ag-1.0h and CNFs/Pd-0.5h exhibited good rate capability [51]. 

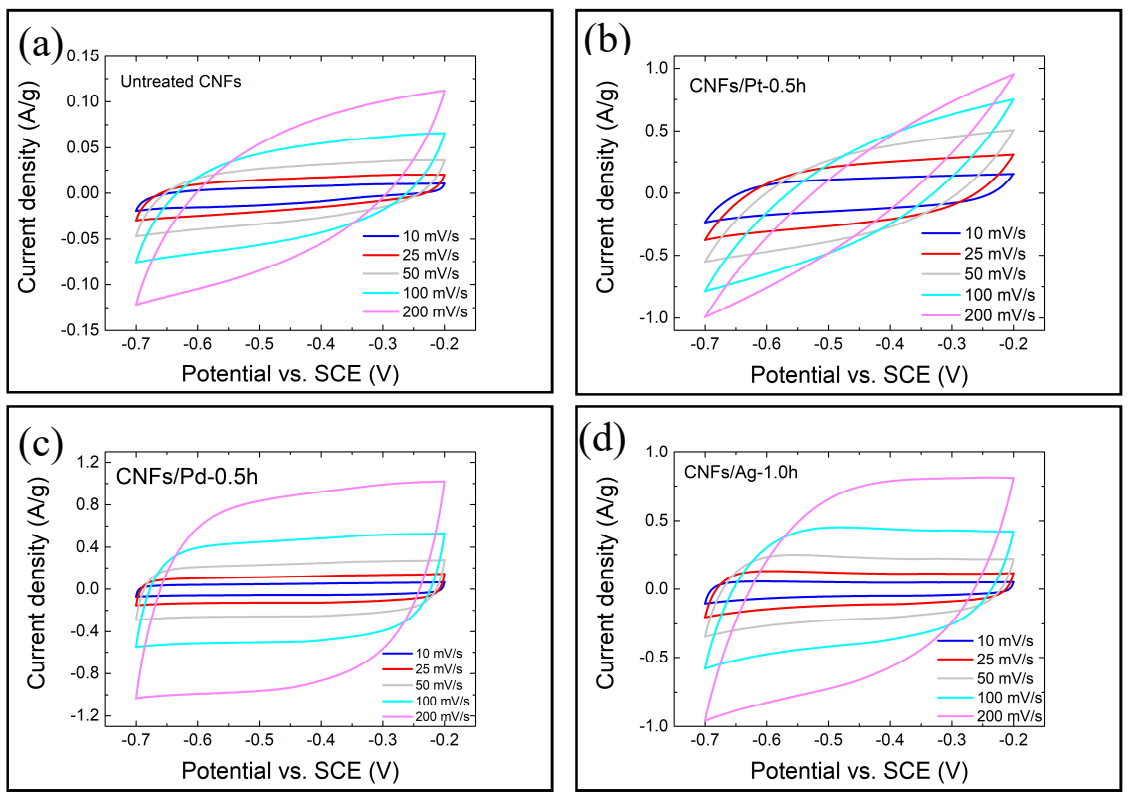

Figure 4. Typical cyclic voltammograms for electrodes made of: (a) untreated CNF; (b) CNFs/Pt-0.5h; (c) $\mathrm{CNFs} / \mathrm{Pd}-0.5 \mathrm{~h}$ and (d) CNFs/Ag-1.0h.

Figure $5 \mathrm{a}-\mathrm{c}$ show that at same scan rates, the specific capacitances of functionalised CNFs were all greater than that of untreated CNFs, and they increased with the sputtering time. The specific capacitances decreased as the scan rate increased, with CNFs/Pt showing the greatest shrinkage. $\mathrm{CNFs} / \mathrm{Pt}-0.5 \mathrm{~h}, \mathrm{CNFs} / \mathrm{Pd}-0.5 \mathrm{~h}$ and CNFs/Ag-1.0h exhibited the best performance within their own groups, and their values were 12.9, 5.7 and 5.6 times larger than that of untreated $\mathrm{CNFs}$ at $10 \mathrm{mV} / \mathrm{s}$, respectively, and 3.0, 13.0 and 10.9 times larger at $200 \mathrm{mV} / \mathrm{s}$. Figure $5 \mathrm{~d}$ illustrates that the specific capacitance of $\mathrm{CNFs} / \mathrm{Pt}-0.5 \mathrm{~h}$ declined dramatically with scan rates, losing approximately $90 \%$ of its capacity at $200 \mathrm{mV} / \mathrm{s}$ compared with that at $10 \mathrm{mV} / \mathrm{s}$, whilst CNFs/Ag-1.0h and CNFs/Pd-0.5h experienced less reductions in capacity as the scan rate increased. The specific capacitance for CNFs/Pd-0.5h only decreased by $27 \%$, indicating its good rate capability [53].
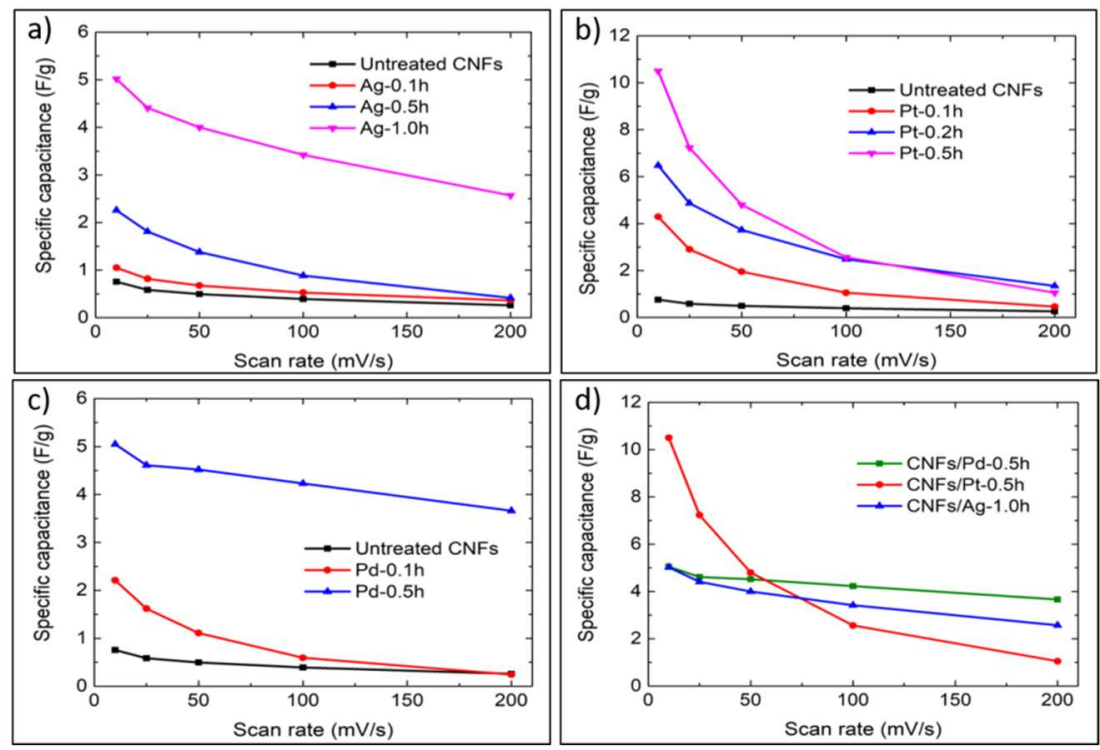

Figure 5. Specific capacitances for: (a) CNFs/Ag series; (b) CNFs/Pt series; (c) CNFs/Pd series; (d) CNFs/Ag-1.0h, CNFs/Pt-0.5h and CNFs/Pd-0.5h, at a series of scan rates (10 to $200 \mathrm{mV} / \mathrm{s}$ ). 
In Figure 6, the capacity of CNFs/Pt-0.5h and CNFs/Pd-0.5h decreased by $15.8 \%$ and $16.9 \%$ of the initial values, respectively, over 2000 cycles. CNFs/Ag-1.0h fluctuates around the initial value. The capacity of qualified SCs commonly falls by less than $20 \%$ of the initial value within their lifetime [54]. The average charging time is: $1.30 \mathrm{~s}$ for Ag- $1.0 \mathrm{~h}$ at current density of $0.8 \mathrm{~A} / \mathrm{g}, 1.40 \mathrm{~s}$ for $\mathrm{Pt}-0.5 \mathrm{~h}$ at $0.8 \mathrm{~A} / \mathrm{g}, 0.77 \mathrm{~s}$ for Pd-0.5h at $2 \mathrm{~A} / \mathrm{g}$. Therefore, the results demonstrated that CNFs $/ \mathrm{Ag}-1.0 \mathrm{~h}$, $\mathrm{CNFs} / \mathrm{Pt}-0.5 \mathrm{~h}$ and CNFs/Pd-0.5h all exhibited good cycle stability for use in at least five years if they were charged and discharged once a day, and the former had the best performance.

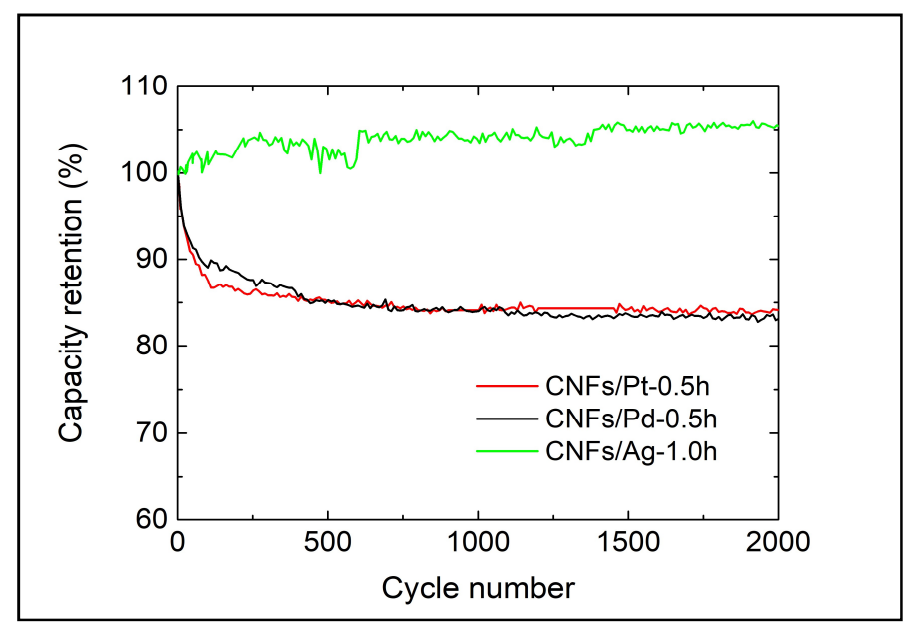

Figure 6. Capacitance retention of $\mathrm{CNFs} / \mathrm{Pd}-0.5 \mathrm{~h}, \mathrm{CNFs} / \mathrm{Pt}-0.5 \mathrm{~h}$ and $\mathrm{CNFs} / \mathrm{Ag}-1.0 \mathrm{~h}$.

In Nyquist plots, the intersection of the projected dash lines and the $x$-axis indicates the equivalent series resistance (ESR) of the electrodes, which is associated with the electrode porous structure and determines their rate capability $[5,55]$. The intersections between the semicircle and the $x$-axis at lower and higher $Z_{\mid \text {real } \mid}$ (e.g., in Figure $7 \mathrm{~b}$ ) represent the equivalent internal resistance $(R s)$ and charge transfer resistance (Rct) of the electrode material, respectively [34]. $R s$ involves the resistance of the electrode material and electrolyte, as well as the contact resistance at the interface between current collector and electrode material. Rct are related with the ion and electron transfer process during the formation of EDL. Figure 7a shows that all functionalised CNFs were shifted to the left and achieved smaller semicircle diameters than untreated CNFs, indicating lower charge transfer resistance of the functionalised CNFs [34]. Also, the slopes of functionalised CNFs were steeper than that of the untreated CNFs, indicating that functionalised CNFs can achieve faster EDL formation which leads to higher rate capability and hence higher power density $[35,36]$. Figure $7 \mathrm{~b}-\mathrm{d}$ show that the $R c t$ and ESR for each kind of materials both decreased with increasing sputtering time, indicating low electron-and-charge transfer resistance and high rate capability, respectively [28]. Figure 7e compares the best material in each group. CNFs/Pd-0.5h exhibited the smallest Rct and ESR, as well as the steepest slope of the diffusion tail, indicating the fastest ion diffusion and penetration in the formation of EDL $[35,36]$. Therefore, it can be inferred that CNFs/Pd-0.5h had the best rate capability, which is consistent with the $\mathrm{CV}$ results. 

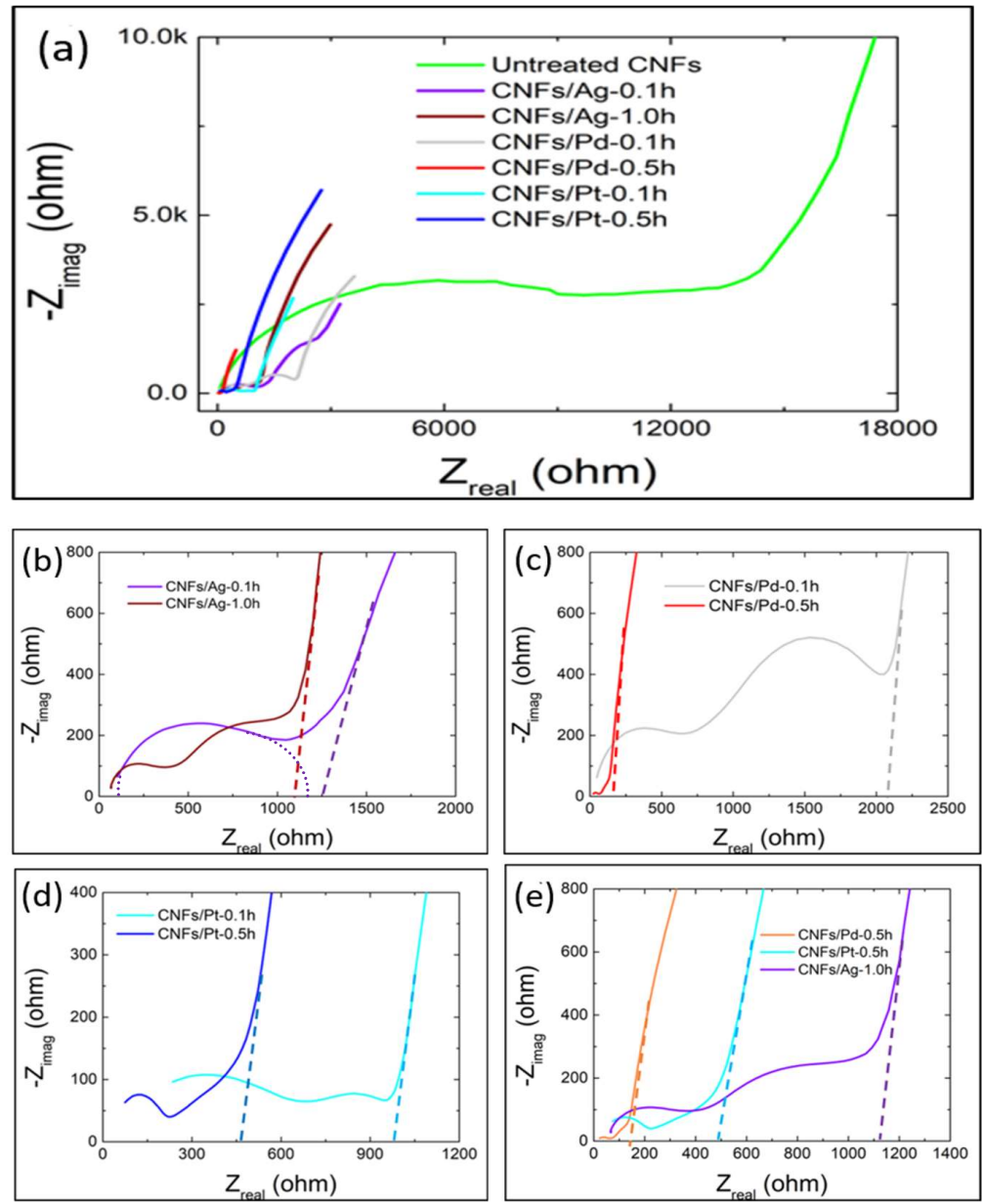

Figure 7. Nyquist plots of: (a) untreated and functionalised CNFs; (b) CNFs/Ag series; (c) CNFs/Pd series and (d) CNFs / Pt series and (e) CNFs/Ag-1.0h, CNFs/Pd-0.5h and CNFs/Pt-0.5h.

\section{Discussion}

\subsection{Effect of the Nanoparticle Deposition on the Electrochemical Performance of CNFs}

The electrochemical performance for the functionalised CNFs displayed a significant improvement possibly due to the corresponding surface structures $[28,55,56]$. The increase of specific capacitance for functionalised CNFs may have attributed to the porous structures. In the SEM images, the valleys existing between the nanoparticles can be considered as porous structures contributing to increased surface area for ion adsorption, therefore improving the specific capacitance. Pd and Ag nanoparticles tended to agglomerate to form larger nanoparticles, whereas Pt nanoparticles piled up evenly on the previous nanoparticles. Consequently, the pore sizes of CNFs/Ag-1.0h and CNFs/Pd-0.5h were in the range of tens of nanometres while that of CNFs/Pt- $0.5 \mathrm{~h}$ was only a few nanometres. The desirable electrode materials present a hierarchical porous structure including macropores $(>50 \mathrm{~nm})$ for accommodating ions, mesopores $(2-50 \mathrm{~nm})$ for facilitating the ion transport, and nanopores $(<2 \mathrm{~nm})$ for boosting the charge storage $[57,58]$. The accessibility of ions from electrolyte into nanopores $(<2 \mathrm{~nm})$ depends on both the ion size and the pore dimension. It is believed that maximum EDL capacitance is yielded when the pore size is approximate to the ion size, and both larger and smaller pores cause a rapid drop in capacitance [59]. The EDL formed at CNFs is mainly due to the adsorption of hydrated $\mathrm{Na}^{+}$ions with an average size of $0.358 \mathrm{~nm}[60,61]$. The low specific capacitance of untreated CNFs may result from unfavourable ion adsorption due to its surface structures. In contrast, a high capacitance was obtained on CNFs/Pt- $0.5 \mathrm{~h}$ at small scan rates possibly because CNFs/Pt- $0.5 \mathrm{~h}$ achieved a large number of nanopores close to the size of $\mathrm{Na}^{+}$ions. Accordingly, $\mathrm{Na}^{+}$ions could access this kind of 
nanopore cavities and form strong interactions within the cavities, resulting in high adsorption and enhanced charge storage [62]. However, the pore size remained constant with sputtering time of up to $0.5 \mathrm{~h}$, and hence, mesopores might be negligible in CNFs/Pt. The fine structure of CNFs/Pt might lead to longer paths for ion diffusion and thus higher charge transfer resistance, hindering fast formation of the EDL which in turn led to poor rate capability $[36,42,43]$. On the contrary, perhaps owing to the large numbers of pores equivalent to mesopores existing in their surface structures, $\mathrm{CNFs} / \mathrm{Pd}$ and CNFs/Ag obtained improved rate capability with the increasing sputtering time. The relatively simple structure of mesopores could shorten the ion diffusion paths and lower the charge transfer resistance effectively, therefore promoting the ion transport and the adsorption/desorption process $[58,63,64]$. Their capacitances were smaller than that of CNFs/Pt-0.5h at low scan rates possibly due to the lack of nanopores [65]. The present results showed that the ASPS technology may provide a way to achieve controllable porous structures and surface properties, enabling the manipulation of electrochemical performance of SCs.

It is noted that the performance of the supercapacitors in our research was not as good as the other literature results. CNFs/Pt-0.5h showed the highest specific capacitance $(\sim 10.5 \mathrm{~F} / \mathrm{g})$ at $10 \mathrm{mV} / \mathrm{s}$, but it was lower than the state-of-art literature results which are normally hundreds of F/g. Nonetheless, this feasibility study shows the potential of the active screen plasma treatments for the energy storage applications, and follow-on work has been planned to optimise the process and improve the performance of the final products.

\subsection{Potential Application of the Functionalised CNFs}

From the CV and EIS analysis, CNFs/Pt-0.5h exhibited the highest specific capacitance only at low scan rates, while CNFs/Pd-0.5h displayed the lowest ESR, excellent rate capability and highest specific capacitance at high scan rates. A small ESR corresponding to fast EDL formation is the key for high rate capability and high power density for SCs [1,28]. CNFs/Ag-1.0h showed lower specific capacitance and rate capability compared to CNFs/Pd-0.5h, but better cycle stability than CNFs/Pd-0.5h, which may contribute to a more consistent performance. Above all, CNFs/Pd-0.5h can be a suitable SC electrode material for short-term use, while CNFs / Ag-1.0h might be appropriate for long-term use.

\section{Conclusions}

The deposition of Ag, Pd and Pt nanoparticles on CNFs via ASPS was successful. The surface morphology of functionalised CNFs depended on target materials and sputtering time. The sizes of $\mathrm{Ag}$ and Pd nanoparticles both increased with sputtering time; their shapes changed from spherical to nodular, and their distribution became less uniform, whereas Pt nanoparticles remained constantly small in size. The cyclic voltammetry performance of CNFs was significantly improved after functionalisation. The specific capacitance of functionalised CNFs increased with sputtering time for each target material. CNFs/Pt-0.5h showed the highest specific capacitance $(\sim 10.5 \mathrm{~F} / \mathrm{g})$ at $10 \mathrm{mV} / \mathrm{s}$ but poor rate capability, while CNFs/Pd-0.5h and CNFs/Ag-1.0h exhibited competitive values at high scan rates. CNFs/Pd-0.5h exhibited the lowest ESR in the EIS analysis, suggesting excellent rate capability, while the excellent life-cycle was achieved on CNFs/Ag-1.0h.

\footnotetext{
Author Contributions: H.D. and X.L. conceived the research concept, provided all research facilities, supervised the research project, and finalised the paper. Z.L. performed the experimental work, collected data, and drafted the manuscript. Y.L. and Z.Z. contributed to some of the experimental work. S.Q. and X.L. helped to interpret the results and improved the manuscript.
}

Funding: The research received funding from the European Union's Horizon 2020 programme under agreement no. GA685844.

Acknowledgments: Zelun Li would like to thank Santiago Corujeira Gallo (Deakin University, Australia) for his very helpful discussion on the experimental set-up and data analysis.

Conflicts of Interest: The authors declare no conflict of interest. 


\section{References}

1. Wang, G.; Zhang, L.; Zhang, J. A review of electrode materials for electrochemical supercapacitors. Chem. Soc. Rev. 2012, 41, 797-828. [CrossRef]

2. Wang, H.; Xu, Z.; Yi, H.; Wei, H.; Guo, Z.; Wang, X. One-step preparation of single-crystalline $\mathrm{Fe}_{2} \mathrm{O}_{3}$ particles/graphene composite hydrogels as high performance anode materials for supercapacitors. Nano Energy 2014, 7, 86. [CrossRef]

3. Erwin, W.R.; Zarick, H.F.; Talbert, E.M.; Bardhan, R. Light trapping in mesoporous solar cells with plasmonic nanostructures. Energy Environ. Sci. 2016, 9, 1577. [CrossRef]

4. Malgras, V.; Ji, Q.; Kamachi, Y.; Mori, T.; Shieh, F.-K.; Wu, K.C.-W.; Ariga, K.; Yamauchi, Y. Templated synthesis for nanoarchitectured porous materials. Bull. Chem. Soc. Jpn. 2015, 88, 1171. [CrossRef]

5. Liu, H.; Huang, Z.; Wei, S.; Zheng, L.; Xiao, L.; Gong, Q. Nano-structured electron transporting materials for perovskite solar cells. Nanoscale 2016, 8, 6209. [CrossRef] [PubMed]

6. Bairi, P.; Minami, K.; Hill, J.P.; Nakanishi, W.; Shrestha, L.K.; Liu, C.; Harano, K.; Nakamura, E.; Ariga, K. Supramolecular differentiation for construction of anisotropic fullerene nanostructures by time-programmed control of interfacial growth. ACS Nano 2016, 10, 8796. [CrossRef] [PubMed]

7. Sakaushi, K.; Antonietti, M. Carbon- and nitrogen-based porous solids: A recently emerging class of materials. Bull. Chem. Soc. Jpn. 2015, 88, 386. [CrossRef]

8. Huang, Z.; Che, S. Fabrication of mesostructured silica materials through Co-structure-directing route. Bull. Chem. Soc. Jpn. 2015, 88, 617. [CrossRef]

9. Yamamoto, E.; Kuroda, K. Colloidal mesoporous silica nanoparticles. Bull. Chem. Soc. Jpn. 2016, 89, 501. [CrossRef]

10. Tabuchi, H.; Urita, K.; Moriguchi, I. Effect of carbon nanospace on charge-discharge properties of Si and SiOx nanoparticles-embedded nanoporous carbons. Bull. Chem. Soc. Jpn. 2015, 88, 1378. [CrossRef]

11. Wu, K.; Lian, T. Quantum confined colloidal nanorod heterostructures for solar-to-fuel conversion. Chem. Soc. Rev. 2016, 45, 3781. [CrossRef] [PubMed]

12. Lewis, N.S. Research opportunities to advance solar energy utilization. Science 2016, 351, aad1920. [CrossRef] [PubMed]

13. Xiao, Z.; Lei, H.; Zhang, X.; Zhou, Y.; Hosono, H.; Kamiya, T. Ligand-hole in [SnI 6 ] unit and origin of band gap in photovoltaic perovskite variant $\mathrm{Cs}_{2} \mathrm{SnI}_{6}$. Bull. Chem. Soc. Jpn. 2015, 88, 1250. [CrossRef]

14. Shibayama, N.; Ozawa, H.; Ooyama, Y.; Arakawa, H. Highly efficient cosensitized plastic-substrate dye-sensitized solar cells with black dye and pyridine-anchor organic dye. Bull. Chem. Soc. Jpn. 2015, 88, 366. [CrossRef]

15. Feng, D.; Lv, Y.; Wu, Z.; Dou, Y.; Han, L.; Sun, Z.; Xia, Y.; Zheng, G.; Zhao, D. Free-standing mesoporous carbon thin films with highly ordered pore architectures for nanodevices. J. Am. Chem. Soc. 2011, 133, 15148-15156. [CrossRef] [PubMed]

16. Zhang, L.L.; Zhao, X.S. Carbon-based materials as supercapacitor electrodes. Chem. Soc. Rev. 2009, 38, 2520-2531. [CrossRef] [PubMed]

17. Xiao, K.; Ding, L.X.; Liu, G.; Chen, H.; Wang, S.; Wang, H. Freestanding, hydrophilic nitrogen-doped carbon foams for highly compressible all solid-state supercapacitors. Adv. Mater. 2016, 28, 5997-6002. [CrossRef]

18. Pushparaj, V.L.; Shaijumon, M.M.; Kumar, A.; Murugesan, S.; Ci, L.; Vajtai, R.; Linhardt, R.J.; Nalamasu, O.; Ajayan, P.M. Flexible energy storage devices based on nanocomposite paper. Proc. Natl. Acad. Sci. USA 2007, 104, 13574-13577. [CrossRef] [PubMed]

19. Zhu, Y.; Murali, S.; Stoller, M.D.; Ganesh, K.J.; Cai, W.; Ferreira, P.J.; Pirkle, A.; Wallace, R.M.; Cychosz, K.A.; Thommes, M.; et al. Carbon-based supercapacitors produced by activation of graphene. Science 2011, 332, 1537. [CrossRef] [PubMed]

20. Peng, X.; Peng, L.; Wu, C.; Xie, Y. Two dimensional nanomaterials for flexible supercapacitors. Chem. Soc. Rev. 2014, 43, 3303. [CrossRef]

21. Peng, L.; Zhu, Y.; Li, H.; Yu, G. Chemically integrated inorganic-graphene two-dimensional hybrid materials for flexible energy storage devices. Small 2016, 12, 6183. [CrossRef] [PubMed]

22. Peng, L.; Zhu, Y.; Chen, D.; Ruoff, R.S.; Yu, G. Two-dimensional materials for beyond-lithium-ion batteries. Adv. Energy Mater. 2016, 6, 1600025. [CrossRef] 
23. Khan, A.H.; Ghosh, S.; Pradhan, B.; Dalui, A.; Shrestha, L.K.; Acharya, S.; Ariga, K. Bull. Two-dimensional (2D) nanomaterials towards electrochemical nanoarchitectonics in energy-related applications. Bull. Chem. Soc. Jpn. 2017, 90, 627-648. [CrossRef]

24. Sengottaiyan, C.; Jayavel, R.; Bairi, P. Cobalt oxide/reduced graphene oxide composite with enhanced electrochemical supercapacitance performance. Bull. Chem. Soc. Jpn. 2017, 90, 955-962. [CrossRef]

25. Dubal, D.P.; Chodankar, N.R.; Kim, D.-H.; Gomez-Romero, P. Towards flexible solid-state supercapacitors for smart and wearable electronics. Chem. Soc. Rev. 2018, 47, 2065-2129. [CrossRef] [PubMed]

26. Yang, C.; Zhou, M.; Xu, Q. Three-dimensional ordered macroporous $\mathrm{MnO}_{2} /$ carbon nanocomposites as high-performance electrodes for asymmetric supercapacitors. Phys. Chem. Chem. Phys. 2013, 15, 19730-19740. [CrossRef]

27. Zhong, C.; Deng, Y.; Hu, W.; Qiao, J.; Zhang, L.; Zhang, J. A review of electrolyte materials and compositions for electrochemical supercapacitors. Chem. Soc. Rev. 2015, 44, 7484-7539. [CrossRef]

28. Yang, L.; Cheng, S.; Ding, Y.; Zhu, X.; Wang, Z.L.; Liu, M. Hierarchical network architectures of carbon fiber paper supported cobalt oxide nanonet for high-capacity pseudocapacitors. Nano Lett. 2012, 12, 321-325. [CrossRef]

29. Frackowiak, E.; Béguin, F. Carbon materials for the electrochemical storage of energy in capacitors. Carbon 2001, 39, 937-950. [CrossRef]

30. Fan, Z.; Yan, J.; Wei, T.; Zhi, L.; Ning, G.; Li, T.; Wei, F. Asymmetric supercapacitors based on graphene $/ \mathrm{MnO}_{2}$ and activated carbon nanofiber electrodes with high power and energy density. Adv. Funct. Mater. 2011, 21, 2366-2375. [CrossRef]

31. Wang, D.-W.; Li, F.; Liu, M.; Lu, G.Q.; Cheng, H.-M. 3D aperiodic hierarchical porous graphitic carbon material for high-rate electrochemical capacitive energy storage. Angew. Chem. 2008, 120, 379-382. [CrossRef]

32. Zhai, Y.; Dou, Y.; Zhao, D.; Fulvio, P.F.; Mayes, R.T.; Dai, S. Carbon materials for chemical capacitive energy storage. Adv. Mater. 2011, 23, 4828-4850. [CrossRef] [PubMed]

33. Raymundo-Piñero, E.; Leroux, F.; Béguin, F. A high-performance carbon for supercapacitors obtained by carbonization of a seaweed biopolymer. Adv. Mater. 2006, 18, 1877-1882. [CrossRef]

34. Kim, C.; Ngoc, B.T.N.; Yang, K.S.; Kojima, M.; Kim, Y.A.; Kim, Y.J.; Endo, M.; Yang, S.C. Self-sustained thin webs consisting of porous carbon nanofibers for supercapacitors via the electrospinning of polyacrylonitrile solutions containing zinc chloride. Adv. Mater. 2007, 19, 2341-2346. [CrossRef]

35. Kim, C.; Yang, K.S.; Kojima, M.; Yoshida, K.; Kim, Y.J.; Kim, Y.A.; Endo, M. Fabrication of electrospinning-derived carbon nanofiber webs for the anode material of lithium-ion secondary batteries. Adv. Funct. Mater. 2006, 16, 2393-2397. [CrossRef]

36. Wang, G.; Pan, C.; Wang, L.; Dong, Q.; Yu, C.; Zhao, Z.; Qiu, J. Activated carbon nanofiber webs made by electrospinning for capacitive deionization. Electrochim. Acta 2012, 69, 65-70. [CrossRef]

37. Al-Saleh, M.H.; Sundararaj, U. A review of vapor grown carbon nanofiber/polymer conductive composites. Carbon 2009, 47, 2-22. [CrossRef]

38. Tibbetts, G.; Lake, M.; Strong, K.; Rice, B. A review of the fabrication and properties of vapor-grown carbon nanofiber/polymer composites. Compos. Sci. Technol. 2007, 67, 1709-1718. [CrossRef]

39. Janas, D.; Koziol, K.K.K. The influence of metal nanoparticles on electrical properties of carbon nanotubes. Appl. Surf. Sci. 2016, 376, 74-78. [CrossRef]

40. Li, C.; Bell, T.; Dong, H. A study of active screen plasma nitriding. Surf. Eng. 2013, 18, 174-181. [CrossRef]

41. Soin, N.; Roy, S.S.; Karlsson, L.; McLaughlin, J.A. Sputter deposition of highly dispersed platinum nanoparticles on carbon nanotube arrays for fuel cell electrode material. Diam. Relat. Mater. 2010, 19, 595-598. [CrossRef]

42. Zacharia, R.; Rather, S.-U.; Hwang, S.W.; Nahm, K.S. Spillover of physisorbed hydrogen from sputter-deposited arrays of platinum nanoparticles to multi-walled carbon nanotubes. Chem. Phys. Lett. 2007, 434, 286-291. [CrossRef]

43. He, Z.; Chen, J.; Liu, D.; Zhou, H.; Kuang, Y. Electrodeposition of Pt-Ru nanoparticles on carbon nanotubes and their electrocatalytic properties for methanol electrooxidation. Diam. Relat. Mater. 2004, 13, 1764-1770. [CrossRef]

44. Lin, Z.; Ji, L.; Zhang, X. Electrodeposition of platinum nanoparticles onto carbon nanofibers for electrocatalytic oxidation of methanol. Mater. Lett. 2009, 63, 2115-2118. [CrossRef]

45. Chen, X.; Xia, J.; Peng, J.; Li, W.; Xie, S. Carbon-nanotube metal-matrix composites prepared by electroless plating. Compos. Sci. Technol. 2000, 60, 301-306. [CrossRef]

46. Faraji, S.; Ani, F.N. The development supercapacitor from activated carbon by electroless plating-A review. Renew. Sustain. Energy Rev. 2015, 42, 823-834. [CrossRef] 
47. Arulepp, M.; Permann, L.; Leis, J.; Perkson, A.; Rumma, K.; Jänes, A.; Lust, E. Influence of the solvent properties on the characteristics of a double layer capacitor. J. Power Sources 2004, 133, 320-328. [CrossRef]

48. Allagui, A.; Freeborn, T.J.; Elwakil, A.S.; Maundy, B.J. Reevaluation of performance of electric double-layer capacitors from constant-current charge/discharge and cyclic voltammetry. Sci. Rep. 2016, 6, 38568. [CrossRef]

49. Corujeira-Gallo, S.; Dong, H. On the fundamental mechanisms of acitve screen plasma nitriding. Vacuum 2010, 84, 321-325. [CrossRef]

50. Numao, S.; Judai, K.; Nishijo, J.; Mizuuchi, K.; Nishi, N. Synthesis and characterization of mesoporous carbon nano-dendrites with graphitic ultra-thin walls and their application to supercapacitor electrodes. Carbon 2009, 47, 306-312. [CrossRef]

51. Hsia, B.; Marschewski, J.; Wang, S.; In, J.B.; Carraro, C.; Poulikakos, D.; Grigoropoulos, C.P.; Maboudian, R. Highly flexible, all solid-state micro-supercapacitors from vertically aligned carbon nanotubes. Nanotechnology 2014, 25, 055401. [CrossRef] [PubMed]

52. Bao, L.; Zang, J.; Li, X. Flexible $\mathrm{Zn}_{2} \mathrm{SnO}_{4} / \mathrm{MnO}_{2}$ core/shell nanocable-carbon microfiber hybrid composites for high-performance supercapacitor electrodes. Nano Lett. 2011, 11, 1215-1220. [CrossRef] [PubMed]

53. Yan, J.; Wei, T.; Shao, B.; Ma, F.; Fan, Z.; Zhang, M.; Zheng, C.; Shang, Y.; Qian, W.; Wei, F. Electrochemical properties of graphene nanosheet/carbon black composites as electrodes for supercapacitors. Carbon 2010, 48, 1731-1737. [CrossRef]

54. Testing Electrochemical Capacitors: Cyclic Charge-Discharge-Stacks. Available online: https://www.gamry. com/application-notes/battery-research/electrochemical-capacitors-cyclic-charge-discharge-and-stacks (accessed on 9 June 2018).

55. Gamby, J.; Taberna, P.L.; Simon, P.; Fauvarque, J.F.; Chesneau, M. Studies and characterisations of various activated carbons used for carbon/carbon supercapacitors. J. Power Sources 2001, 101, 109-116. [CrossRef]

56. Gui, Z.; Zhu, H.; Gillette, E.; Han, X.; Rubloff, G.W.; Hu, L.; Lee, S.B. Natural cellulose fiber as substrate for supercapacitor. ACS Nano 2013, 7, 6037-6046. [CrossRef] [PubMed]

57. Cai, J.; Niu, H.; Wang, H.; Shao, H.; Fang, J.; He, J.; Xiong, H.; Ma, C.; Lin, T. High-performance supercapacitor electrode from cellulose-derived, inter-bonded carbon nanofibers. J. Power Sources 2016, 324, 302-308. [CrossRef]

58. Liu, C.; Yu, Z.; Neff, D.; Zhamu, A.; Jang, B.Z. Graphene-based supercapacitor with an ultrahigh energy density. Nano Lett. 2010, 10, 4863-4868. [CrossRef] [PubMed]

59. Liu, C.; Li, F.; Ma, L.P.; Cheng, H.M. Advanced materials for energy storage. Adv. Mater. 2010, 22, E28-E62. [CrossRef]

60. Largeot, C.; Portet, C.; Chmiola, J.; Taberna, P.-L.; Gogotsi, Y.; Simon, P. Relation between the ion size and pore size for an electric double-layer capacitor. JACS 2008, 130, 2730-2731. [CrossRef]

61. Volkov, A.G.; Paula, S.; Deamer, D.W. Two mechanisms of permeation of small neutral molecules and hydrated ions across phospholipid bilayers. Bioelectrochem. Bioenerg. 1997, 42, 153-160. [CrossRef]

62. Nightingale, E.R. Phenomenological theory of ion solvation. Effective radii of hydrated ions. J. Phys. Chem. 1959, 63, 1381-1387. [CrossRef]

63. Yuan, L.; Xiao, X.; Ding, T.; Zhong, J.; Zhang, X.; Shen, Y.; Hu, B.; Huang, Y.; Zhou, J.; Wang, Z.L. Paper-based supercapacitors for self-powered nanosystems. Angew. Chem. Int. Ed. Engl. 2012, 51, 4934-4938. [CrossRef] [PubMed]

64. Zhi, M.; Xiang, C.; Li, J.; Li, M.; Wu, N. Nanostructured carbon-metal oxide composite electrodes for supercapacitors: A review. Nanoscale 2013, 5, 72-88. [CrossRef]

65. Yamada, H.; Nakamura, H.; Nakahara, F.; Moriguchi, I.; Kudo, T. Electrochemical study of high electrochemical double layer capacitance of ordered porous carbons with both meso/macropores and micropores. J. Phys. Chem. C 2007, 111, 227-233. [CrossRef]

(C) 2018 by the authors. Licensee MDPI, Basel, Switzerland. This article is an open access article distributed under the terms and conditions of the Creative Commons Attribution (CC BY) license (http:/ / creativecommons.org/licenses/by/4.0/). 